\title{
Short-term markers of DNA damage among roofers who work with hot asphalt
}

\author{
Berrin Serdar ${ }^{1,2,6^{*}}$, Stephen Brindley ${ }^{1}$, Greg Dooley ${ }^{3}$, John Volckens ${ }^{4}$, Elizabeth Juarez-colunga ${ }^{5}$ and Ryan Gan ${ }^{2}$
}

\begin{abstract}
Background: Roofers are at increased risk for various malignancies and their occupational exposures to polycyclic aromatic hydrocarbons (PAHs) have been considered as important risk factors. The overall goal of this project was to investigate the usefulness of phosphorylated histone $\mathrm{H} 2 \mathrm{AX}(\mathrm{\gamma H} 2 \mathrm{AX})$ as a short-term biomarker of DNA damage among roofers.

Methods: Blood, urine, and dermal wipe samples were collected from 20 roofers who work with hot asphalt before and after $6 \mathrm{~h}$ of work on Monday and Thursday of the same week ( 4 sampling periods). Particle-bound and gas-phase PAHs were collected using personal monitors during work hours. YH2AX was quantified in peripheral lymphocytes using flow cytometry and 8-hydroxy-2-deoxyguanosine (8-OHdG) was assessed in urine using ELISA. General linear mixed models were used to evaluate associations between DNA damage and possible predictors (such as sampling period, exposure levels, work- and life-style factors). Differences in mean biomarker and DNA damage levels were tested via ANOVA contrasts.
\end{abstract}

Results: Exposure measurements did not show an association with any of the urinary biomarkers or the measures of DNA damage. Naphthalene was the most abundant PAH in gas-phase, while benzo(e)pyrene was the most abundant particle-bound PAH. Post-shift levels of $\mathrm{YH} 2 \mathrm{AX}$ and 8-OHdG were higher on both study days, when compared to pre-shift levels. Cigarette smoking was a predictor of $\mathrm{yH} 2 \mathrm{AX}$ and urinary creatinine was a predictor of urinary 8-OHdG. Between-subject variance to total variance ratio was $35.3 \%$ for $\mathrm{yH} 2 \mathrm{ax}$ and $4.8 \%$ for $8-\mathrm{OHdG}$.

Conclusion: $\mathrm{\gamma H} 2 \mathrm{AX}$ is a promising biomarker of DNA damage in occupational epidemiology studies. It has a lower within-subject variation than urinary $8-\mathrm{OHdG}$ and can easily be detected in large scale groups. Future studies that explore the kinetics of $\mathrm{H} 2 \mathrm{AX}$ phosphorylation in relation to chemical exposures may reveal the transient and persistent nature of this sensitive biomarker of early DNA damage.

Keywords: Polycyclic aromatic hydrocarbons, PAHs, Biomarkers, 8-hydroxy-deoxyguanosine, yH2AX, DNA double strand breaks

\section{Background}

Workers around the world experience daily exposures to potentially carcinogenic chemicals. Identifying the role of these exposures in cancer development later in life has been a major challenge in occupational epidemiology. Estimating the exposure-cancer association becomes more complicated by simultaneous exposures to other environmental and lifestyle factors. A further challenge is the long

\footnotetext{
*Correspondence: Berrin.Serdar@ucdenver.edu

'Department of Environmental and Occupational Health, Colorado School of Public Health, University of Colorado Denver, Denver, USA

${ }^{2}$ Department of Epidemiology, Colorado School of Public Health, University

of Colorado Denver, Denver, USA

Full list of author information is available at the end of the article
}

latency period between carcinogenic exposure and cancer diagnosis. Many times occupational studies rely on estimates of current exposures and their association to shortterm markers of health effects. Among these markers, measures of DNA damage are viewed as reliable indicators of increased cancer risk [1], as they represent early signs of endogenous genomic instability at the tissue level and can help identify precancerous lesions which in turn can improve prevention efforts [2].

Roofers are at increased risk for different malignancies such as lung, bladder, stomach, skin and buccal cavity cancers, and leukemia [3-10]. Exposure to asbestos, polycyclic aromatic hydrocarbons (PAHs) and high rates 
of cigarette smoking have all been considered possible crucial risk factors among roofers $[8,11]$. Work with hot asphalt is an important source of PAH exposure in this group and has been linked to DNA strand breaks, DNA adducts and sister chromatid exchanges [10, 12-14]. Asphalt is a mixture of hundreds of different chemical compounds, containing some known human carcinogens such as benzo(a)pyrene $(\mathrm{BaP})$, which can be absorbed through inhalation, dermal contact, or ingestion [15]. Since many PAHs in asphalt are ubiquitous in the environment, distinguishing occupational exposures from environmental (non-occupational) exposures is difficult. PAHs in air occur both in gaseous and particulate phase: smaller molecular weight PAHs, such as the 2-ring naphthalene, are found predominantly in the gas phase whereas higher molecular weight compounds, such as the 4-ring pyrene, are found mainly in the particulate phase [16]. Accurate measurement of individual PAHs in air has been difficult due to the complexity of the mixtures and the sensitivity of some individual PAHs to environmental or analytical conditions [16, 17]. Additionally, dermal contact can be a significant route of exposure in many work environments, including roofing [18-21]. Because measures of external PAH exposure have limitations, biological monitoring of PAHs has also been used for risk estimation [22-24]. However, studies monitoring exposures to high molecular weight PAHs have similar challenges, such as low levels of exposures, undetectable levels of biomarkers, complicated analytical techniques with low sensitivity, and weak correlations between exposure and biomarker levels [24-27]. We and others have previously proposed that urinary metabolites of the more volatile and abundant PAHs, such as naphthalene, could theoretically increase the sensitivity of the analytical procedures [27-29].

Exposure to PAHs can increase reactive oxygen species (ROS) formation in the body. When the cellular antioxidant defense system is disturbed, the increased amount of ROS can cause oxidative damage to biomolecules such as DNA, proteins and lipids. Recent studies have supported the link between insufficient cellular defense towards oxidative DNA damage and increased susceptibility to cancer development [30-33]. Urinary 8-hydroxy2 '-deoxyguanosine (8-OHdG), a byproduct of DNA repair and oxidative damage, is a reliable biomarker of general oxidative stress and DNA damage related to occupational and environmental exposures [31, 34, 35]. Very few studies have quantified occupational PAH exposures and concurrent DNA damage. Among these, studies that examined asphalt exposure have mainly looked at highway maintenance workers [10, 12-14, 36, 37]. We have previously assessed 8-OHdG in roofers who work with hot asphalt and observed a good correlation with this marker and 1-OHPyr at the end of the work-shift [38]. However, a major limitation of $8-\mathrm{OHdG}$ is that many individual (metabolic events, life style factors such as smoking and alcohol consumption) and environmental (e.g., UV radiation) factors can cause levels of 8-OHdG to fluctuate [31, 35, 39].

Double-strand DNA breaks have also been linked to PAH exposures; this form of DNA damage can be measured using phosphorylated histone $\mathrm{H} 2 \mathrm{AX}(\gamma \mathrm{H} 2 \mathrm{AX})$ in individual cells [40]. Increased levels of cellular $\gamma \mathrm{H} 2 \mathrm{AX}$ have been associated with exposure to radiation [41-43], cigarette smoke [44, 45], particulate matter [46], and other toxic agents $[45,47,48]$. In fact, $\gamma \mathrm{H} 2 \mathrm{AX}$ is considered to be a sensitive marker of DNA damage and increased cancer risk $[49,50]$. One limitation for using $\gamma \mathrm{H} 2 \mathrm{AX}$ in population studies has been the labor-intensive analytic techniques. Immunofluorescence microscopy is the most commonly used method for detecting $\gamma \mathrm{H} 2 \mathrm{AX}$, although flow cytometry, Western blotting and ELISA have also been used [51]. Both microscopy and cytometrybased methods have been suitable to evaluate $\gamma \mathrm{H} 2 \mathrm{AX}$ formation. The image cytometry and Laser Scanning Microscopy (LSC) methods have an advantage over flow cytometry because they enable counting and sizing of $\gamma \mathrm{H} 2 \mathrm{AX}$ foci, but they are also expensive and time consuming [52, 53]. A study recently proposed the use of blood smears prepared from a drop of blood, which may provide a feasible method of immunostaining in large scale studies [53].

Before a biomarker can be comfortably used in epidemiology studies, it needs to be validated based on the following criteria: 1) The relationship between the biomarker and exposure in question, 2) The formation, distribution and elimination of the biomarker in humans, 3) Variation of the biomarker between- and within- study participants, 4) Baseline values of the biomarker in the general population, and finally 5) Cost and difficulty of analytical techniques [54]. Here, we used flow cytometry to quantify $\gamma \mathrm{H} 2 \mathrm{AX}$ from peripheral blood lymphocytes of roofers who work with hot asphalt. The overall goal of this project was to determine the usefulness of $\gamma \mathrm{H} 2 \mathrm{AX}$ as a shortterm marker of DNA damage in roofers exposed to PAHs in comparison to the widely used urinary 8-OHdG.

\section{Methods}

Study population and sample collection

Twenty roofers employed by one roofing company were recruited. The study site was a roof replacement project located in Colorado Springs, Colorado and was visited by the field study team over four weeks between July and September of 2013. Potential participants were informed about the study at the site and those who signed the informed consent under University of Colorado's IRB (COMIRB) approved protocol (COMIRB Protocol \# 12-0443) were recruited. Each week, a new group of workers participated in the study over two workdays: 
Monday and Thursday. Study questionnaires were administered before and after the work-shift in either English or Spanish; the latter applied by a Spanish speaking interviewer. Biological samples (urine and blood) were collected before and after $6 \mathrm{~h}$ of work. Study participants also provided hand wipes (with $3 \mathrm{ml}$ sun flower oil) at each sampling period. Information on personal characteristics (age, height, weight, etc.), life-style factors (smoking, dietary $\mathrm{PAH}$ exposures, alcohol consumption), use of protective equipment during the study day (such as gloves, masks, etc.) and specific work tasks performed during the day (removing old roof, applying new roof) were collected via questionnaires. The before-work questionnaire focused on non-occupational sources of PAH exposures and the after-work questionnaires contained more detailed questions on work practices. Both of these questionnaires are provided in Additional file 1.

After the completion of morning questionnaires and collection of biological samples, the participants were given lightweight vests with air monitors to collect air samples from within each worker's breathing zone air during the shift. The participants were then asked to return to their work. After $6 \mathrm{~h}$ of work participants returned the vests with the air monitors. The total number of samples collected from 20 participants is as follows: 79 urine, 79 blood, 40 air, and 79 dermal wipes. One of the participants had to leave the site on the second study day due to a family emergency and could not provide samples that afternoon (period 4).

\section{Air PAHs}

Polycyclic aromatic hydrocarbons (PAHs) in ambient air were measured within the breathing zone of workers via personal sampling. Particle-bound PAHs, 4-ring and above, were collected using personal sampling pumps (SKC XR5000) fitted with $\mathrm{PM}_{2.5}$ sampling inlets (model 2.05, Mesa Labs, Inc.) and $37 \mathrm{~mm}$ Teflon filters. Gasphase PAHs were collected immediately downstream of the filters using standard adsorbent tubes (XAD-2, 2 section, $75 / 150 \mathrm{mg}$ sorbent). Method details are provided in Additional file 2.

\section{PAH metabolites and creatinine in urine}

PAH metabolites were analyzed using an automated solid-phase extraction based on a method developed by Romanoff [55]. Details for the analysis of metabolites and urine creatinine are presented in Additional file 2.

\section{PAH levels on dermal wipes}

Dermal exposure samples were collected using a previously published hand washing method with sunflower oil [56]. Details are presented in Additional file 2.

\section{Lymphocyte $\mathrm{\gamma H} 2 \mathrm{AX}$ flow cytometry}

Methodological details on processing of peripheral blood samples are described in Additional file 2. Lymphocyte samples $(n=80)$ were tested to evaluate levels of $\gamma \mathrm{H} 2 \mathrm{AX}$. This method was optimized by treating fresh lymphocytes, in triplicate from one volunteer who was not a roofer, with various amounts of $\mathrm{H}_{2} \mathrm{O}_{2}(0.02-0.24 \mathrm{mM})$ and freezing via the same method described above. Frozen samples were thawed in a $37{ }^{\circ} \mathrm{C}$ water bath (VWR, Radnor, Pennsylvania) and 500,000 cells were added to wells in a round-bottom 96 well plate (Nunc, Roskilde, Denmark). Freezing media was removed and cells were washed 3 times with PBS. All washes and buffer removals involved a $600 \mathrm{~g}$ spin for five minutes at room temperature. Cells were then fixed with $200 \mu \mathrm{L}$ BD Cytofix fixation buffer (BD Biosciences) and incubated for $15 \mathrm{~min}$ at room temperature. Next, the fixative was removed, and cells were washed twice with $200 \mu \mathrm{L}$ of PBS. Cells were then permeabilized with $200 \mu \mathrm{l}-20{ }^{\circ} \mathrm{C}$ Perm Buffer III (BD Biosciences) for $5 \mathrm{~min}$ at RT. After one wash in $200 \mu \mathrm{L}$ of 1x perm/wash buffer (BD Biosciences), $200 \mu \mathrm{l}$ of $1 \mathrm{x}$ stain buffer (BD Biosciences) was added to each well to block non-specific binding. After $20 \mathrm{~min}$ at room temperature the cells were washed two times with $200 \mu \mathrm{l}$ of Perm/ Wash buffer. Next, $100 \mu \mathrm{l}$ stain buffer and $5 \mu \mathrm{l}$ BD antibody (557782, Alexa Fluor 488 Mouse IgG1 k Isotype control and 560445, Alexa Fluor 488 Mouse anti- $\gamma \mathrm{H} 2 \mathrm{AX}$ IgG1 $\mathrm{\kappa}$ ) were added and cells were incubated for $60 \mathrm{~min}$ at room temperature in the dark. After antibody removal, wells were washed three times with $200 \mu \mathrm{l}$ of $1 \mathrm{x}$ perm/ wash buffer. Finally, the cells were resuspended in $300 \mu \mathrm{l}$ FACS fix (1x PBS with $0.1 \%$ sodium azide and $4 \%$ formaldehyde) and read with CFlow Plus software on a C6 flow cytometer (Accuri Cytometers, Ann Arbor, Michigan). All samples were run in triplicate and results are given in mean fluorescence intensity (MFI) of the lymphocyte gated FL1 channel (Fig. 1). Control antibody values were subtracted from $\gamma \mathrm{H} 2 \mathrm{AX}$ antibody values to determine final MFI for each sample. Positive control samples were obtained by treating volunteer lymphocytes with hydrogen peroxide $\left(\mathrm{H}_{2} \mathrm{O}_{2}\right)$. Plots for publication were made using the FCS Express4 Flow Research Edition software. Figure 2 presents $\gamma \mathrm{H} 2 \mathrm{AX}$ MFI in peripheral blood lymphocytes of one laboratory volunteer (not a roofer and nonsmoker) collected over three consecutive days and treated with varying doses $(0.02-0.25 \mathrm{mM})$ of $\mathrm{H} 2 \mathrm{O} 2$ on each day. We observed a positive dose-response between $\mathrm{H} 2 \mathrm{O} 2$ treatment and $\gamma \mathrm{H} 2 \mathrm{AX}$ MFI that ranged from $692 \mathrm{MFI}$ at zero $\mathrm{H} 2 \mathrm{O} 2$ to $4000 \mathrm{MFI}$ at $0.25 \mathrm{mM}$ H2O2 (Fig. 2).

\section{Statistical analyses}

All statistical analyses were conducted using SAS system software (version 9.4; SAS Institute, Cary, NC) at a 


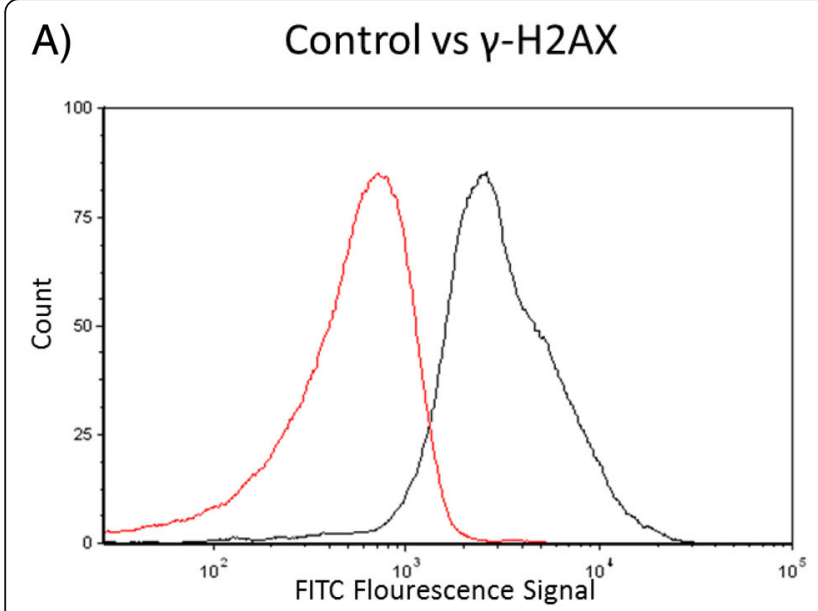

B)

Lymphocyte Gate

Fig. 1 Representative gating for $\gamma$-H2AX assay. a Control antibody stained sample vs. $\gamma$-H2AX stained sample (gated on P1); b Lymphocyte Gate (P1)

significance level of 0.05 . All tests were performed after (natural) logarithmic transformation of urinary analytes (PAH metabolites, creatinine, 8-OHdG), $\gamma \mathrm{H} 2 \mathrm{AX}$ and $\mathrm{PAH}$ levels (air and dermal wipe) to satisfy the normality assumption, and data were summarized as geometric means (GMs) and geometric standard deviations (GSDs). Average levels of naphthalene and pyrene in personal breathing zone samples or on dermal wipes were compared between the two study days or between smokers and nonsmokers for each day, using Student's t-tests. Specific contrasts (with alpha $=0.05$ ) were applied to test for differences in log-transformed mean levels of urinary biomarkers and

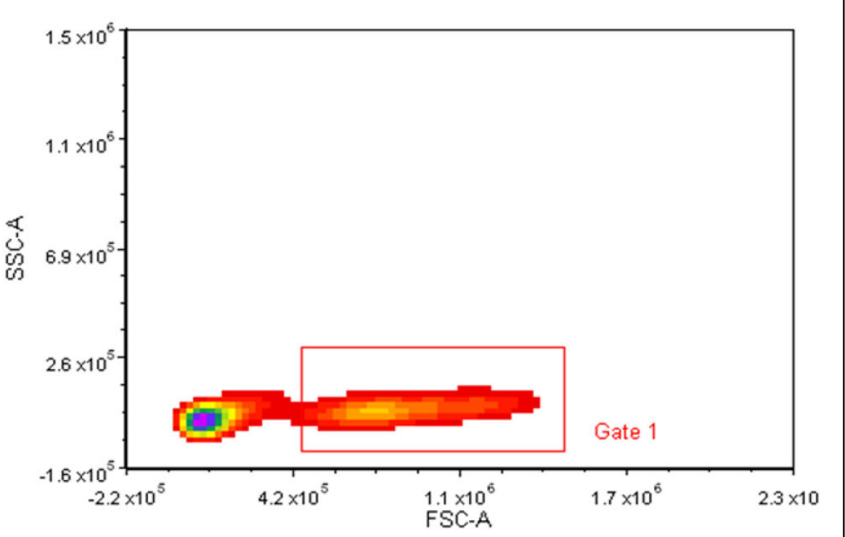
1) 
LOD, while naphthalene was detected in all of the XAD samples. For dermal wipes, $3.5 \%$ for naphthalene samplers were below LOD and pyrene was detected in all of the samples. Measurements of $\gamma \mathrm{H} 2 \mathrm{AX}$ (lymphocytes) and 8-OHdG (urine) were above detection limit for all of the samples. For urinary biomarkers: 1-OHPyr was below LOD in $24 \%$ of the samples while 1-OHNap was below LOD in one urine sample (1.2 \%). 2-OHNap and creatinine were both detected in all of the urine samples. For samples that were below the LOD, a proxy measurement was assigned using the value of LOD $/ \sqrt{ } 2$ before statistical analyses [57].

Information for a number of general and work-related variables was collected via questionnaires (Additional file 1). The general variables included the following: cigarette smoking status, demographic variables (age, race/ethnicity), possible dietary exposure to PAHs (number of servings for consumption of grilled, broiled or smoked meat/fish/chicken within the last $24 \mathrm{~h}$ ), and number of alcoholic drinks consumed within the last $24 \mathrm{~h}$. The work related variables included the following: removal of old roof (yes/no), application of new roofing (yes/no), work with hot asphalt (yes/no), work as kettleman (yes/no), exposure to diesel exhaust during day's work (yes/no), percent of time when gloves or a face mask was used, if clothing was short-sleeved or long-sleeved, if hands were washed anytime during work prior to sampling (yes/no), if any solvents or other chemicals were used to clean skin (yes/ no), and if the roofer experienced skin burn due to contact with hot asphalt (yes/no).

Repeated-measures general linear mixed modeling (PROC MIXED) was used to examine associations between DNA damage measures ( $\gamma \mathrm{H} 2 \mathrm{AX}$ and $8-\mathrm{OHdG}$ ) and sampling period (before/after work on two separate sampling days) adjusting for confounders. For the general linear mixed models only confounders with values at the four different sampling periods were considered. Candidate variables that were considered amounted to eight variables for the model of $\gamma \mathrm{H} 2 \mathrm{AX}$ (urinary biomarkers: 1-OHNap, 2-OHNap, and 1-OHPyr; dermal levels of naphthalene and pyrene; sampling period, age, and cigarette smoking status), and nine variables for the model of urinary 8-OHdG (urinary biomarkers: 1OHNap, 2-OHNap, and 1-OHPyr; dermal levels of naphthalene and pyrene; sampling period, age, and cigarette smoking status, and urinary creatinine), plus the two-way interactions between urinary biomarkers and cigarette smoking in both models. The most likely candidate variables were screened as follows. First, DNA damage measures were regressed on each covariate separately and variables that suggested significant contributions $(p<0.10)$ were retained. Backward selection of all retained independent variables and their plausible two-way interactions were used to achieve final models (using a significance level of $p<0.05)$. Multivariable models had the general form:

$$
Y_{i j}=\alpha+b_{i}+\sum_{k=1}^{p} \beta_{k} X_{i k}+f\left(\text { period }_{j}\right)+\varepsilon_{i j}
$$

where $Y_{i}$ represents the subject-specific mean of logtransformed levels of $\gamma \mathrm{H} 2 \mathrm{AX}$ (or 8-OHdG) for the $i^{t h}$ subject at sampling period $j^{h}, \alpha$ is the intercept representing the average level of $Y_{i}$ when all independent variables are zero for an average worker, $b_{i}$ is the random intercept for subject $\mathrm{i}$ that captures the heterogeneity between individuals, $\beta_{k}$ is the regression coefficient for the $k^{t h}$ independent variable $X_{i k}$ for the $i^{t h}$ subject, and $\varepsilon_{i j}$ is the error term. Given the sample size of 80 measurements from 20 individuals, a linear mixed model with about 4-6 predictors will likely be a stable model. Estimates of the percentage of variance explained by each of the significant covariates in the linear mixed models were calculated using the conditional and marginal formulas of $\mathrm{R}^{2}$ [58]. The intraclass correlation coefficients (ICC) were estimated for final models of each DNA damage measure, using ICC = between-subject variance/(between-subject variance + within-subject variance).

\section{Results}

Levels of DNA damage markers were at higher concentrations in samples collected after work when compared to those observed before work. The overall difference between post-shift and pre-shift levels was 1.7-fold for urinary 8-OHdG (3972.3 and $2367.3 \mu \mathrm{g} / \mathrm{g}$ creatinine, respectively, $p$-value $<0.0001$ for difference). When divided by smoking status, post-shift levels of 8 -OHdG remained to be higher than those observed pre-shift in nonsmokers (3714.5 and $2368.5 \mu \mathrm{g} / \mathrm{g}$ creatinine, respectively) and in smokers (4146.4 and $2344.9 \mu \mathrm{g} / \mathrm{g}$ creatinine, respectively), difference was statistically significant for both groups $(p<0.05)$. The overall difference between post-shift and pre-shift levels was smaller for $\gamma \mathrm{H} 2 \mathrm{AX}$ (1157.7 and 1229.7 MFI, respectively, $p=0.048$ for test of difference) and remained small in nonsmokers (1164.4 and 1107.7 MFI, respectively, $p=0.2)$ and in smokers (1286.9 and 1188.0 MFI, respectively, $p=0.09$ ).

Figure 3 presents average $\gamma \mathrm{H} 2 \mathrm{AX}$ MFI in peripheral blood lymphocytes collected from roofers during the study. Average pre-shift MFI was 1081 on Monday and 1150 on Thursday among nonsmokers. On Monday, we observed an increase in $\gamma \mathrm{H} 2 \mathrm{AX}$ MFI over the work shift in both smokers and nonsmokers (Fig. 3a). On Thursday, however, only levels in smokers increased during work hours while levels of $\gamma \mathrm{H} 2 \mathrm{AX}$ in nonsmokers remained similar after work (Fig. 3b). When average levels were compared using two-way ANOVA, the highest levels of 


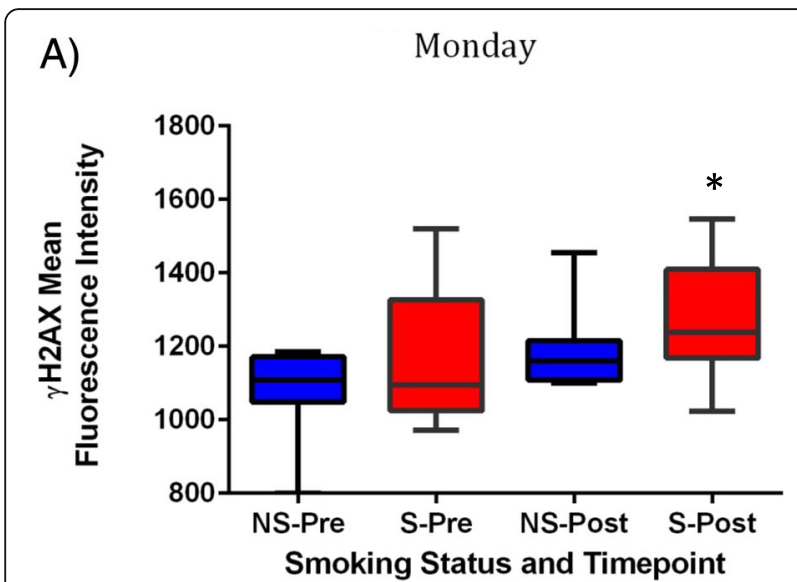

B)

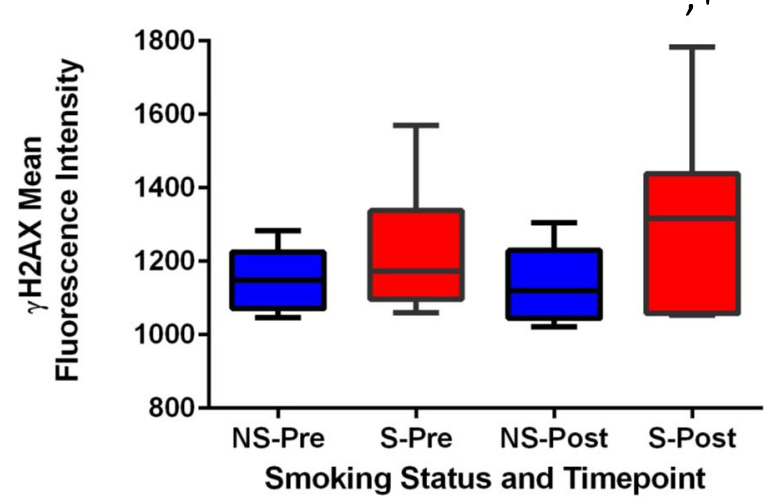

Fig. 3 Mean fluorescence intensity values of $\mathrm{\gamma}-\mathrm{H} 2 \mathrm{AX}$ for nonsmokers $(n=8)$ and smokers $(n=12)$ by study day and sampling time (pre and post work-shift). a Monday b Thursday. NS = nonsmokers, $\mathrm{S}=$ smokers, Pre: pre-shift, Post: post-shift. ${ }^{*} p<0.05$ when compared to means of nonsmokers, pre-shift within same sampling day. $+p<0.05$ when compared to levels of non-smokers after work within same study day

$\gamma \mathrm{H} 2 \mathrm{AX}$ MFI were observed in smokers after work, while the lowest levels were observed among nonsmokers before work (Fig. 3).

Among PAHs in the gaseous phase (obtained via XAD adsorbent tubes), naphthalene was the most abundant $\mathrm{PAH}$, quantified in all of the samples. Pyrene on the other hand, was only quantified in $57.5 \%$ of the XAD samples. For PAH measurements obtained from filters (representing particulate phase) the most abundant compound was benzo(e)pyrene quantified in $65 \%$ of all samples, followed by naphthalene quantified in $57.5 \%$. Only $35 \%$ of filter samples had quantifiable levels of pyrene. Table 1 presents geometric mean levels of selected PAHs by study day. Cigarette smokers had higher exposure levels for most PAHs, particularly on Thursday, but the differences between levels in smokers
Table 1 Geometric means (and geometric standard deviations) of PAH measures in personal air samples $\left(\mathrm{ng} / \mathrm{m}^{3}\right)$ collected over the work hours (A) and PAH levels in dermal wipes ( $\mu \mathrm{g} /$ wipe) collected before and after work (B)

A. Airborne exposure measurements $(n=40)$

$$
\begin{array}{ll}
\text { Naphthalene }\left(\mathrm{ng} / \mathrm{m}^{3}, \mathrm{XAD}\right) & 361.4(2.9) \\
\text { Pyrene }\left(\mathrm{ng} / \mathrm{m}^{3}, \mathrm{XAD}\right) & 2.3(7.5) \\
\text { Naphthalene }\left(\mathrm{ng} / \mathrm{m}^{3}, \mathrm{FLT}\right) & 0.78(2.7) \\
\text { Benzo(e)pyrene }\left(\mathrm{ng} / \mathrm{m}^{3}, \mathrm{FLT}\right) & 3.5(8.9)
\end{array}
$$

B. Dermal exposure measurements collected before $(n=40)$ and after the work shift $(n=39)$

$\begin{array}{lll}\text { PAH }(\mu \mathrm{g} / \text { wipe }) & \text { Before } & \text { After } \\ \text { Naphthalene } & 0.32(1.3) & 0.32(1.3) \\ \text { Pyrene } & 0.15(1.5) & 0.35(2.4)^{*}\end{array}$

FLT PAHs in particulate phase from filters, XAD PAHs in gaseous phase from XAD adsorbent tubes

${ }^{*} p<0.0001$ when compared to before work levels

and nonsmokers were not statistically significant (see Additional file 3: Table S1).

Levels of naphthalene on dermal wipes did not differ significantly before or after the work on both study days (Table 1B). Levels of pyrene, however, significantly increased over work hours (Table 1B).

Table 2 presents geometric mean levels of urinary biomarkers before and after work by week day. On Monday, levels of 1-OHPyr and 8-OHdG were higher in the afternoon (3- and 2-fold, respectively), when compared to levels observed in morning samples. Urinary 1-OHPyr levels increased during work on Thursday as well, but this was not observed for urinary 1 - and 2-OHNap (Table 2).

All urinary biomarkers were higher after work on Monday in both smokers and nonsmokers, but the postshift to pre-shift difference was statistically significant only for urinary 1-OHPyr and $8-\mathrm{OHdG}$ in smokers (Additional file 3: Table S2). On Thursday, levels of urinary biomarkers increased over work hours in nonsmokers, with a statistically significant difference observed

Table 2 Geometric means (and geometric standard deviations) of urinary biomarkers ( $\mu \mathrm{g} / \mathrm{g}$ creatinine) and of $\gamma \mathrm{H} 2 \mathrm{AX}$ (from lymphocytes) in samples collected before and after work on both study days

\begin{tabular}{lllllll}
\hline \multirow{2}{*}{ Biomarker } & Monday & & & \multicolumn{2}{l}{ Thursday } \\
\cline { 2 - 3 } \cline { 6 - 6 } & Before $(n=20)$ & After $(n=20)$ & & Before $(n=20)$ & After $(n=19)$ \\
\hline 1-OHNap & $13,766.6(4.3)$ & $24,343.0(3.2)$ & & $17,500.8(2.8)$ & $18,769.7(4.5)$ \\
2-OHNap & $54,176.4(2.0)$ & $73,130.4(2.5)$ & $73,130.4(2.0)$ & $73,130.4(2.1)$ \\
1-OHPyr & $706.3(3.7)$ & $2100.6^{*}(3.0)$ & $1032.8(4.5)$ & $1790.0(3.7)$ \\
8-OHdG & $2186.4(1.8)$ & $4105.2^{*}(1.4)$ & & $2565.7(1.4)$ & $3866.1^{*}(1.5)$ \\
YH2AX (MFI) & $1118.8(1.2)$ & $1224.1^{*}(1.1)$ & & $1188.0(1.1)$ & $1236.4(1.2)$ \\
\hline
\end{tabular}

${ }^{*} p<0.05$ when compared to pre-shift levels within the same day. MFI mean fluorescence intensity 
for urinary 8 -OHdG $(p=0.005$, Additional file 3: Table S2). For smokers, the pattern was different; highest levels of urinary 1- and 2-OHNap were observed in the morning and diminished during work hours (Additional file 3: Table S2).

Pearson correlation coefficients between pairs of log-transformed values of PAHs observed in air, dermal wipes, and in urine and post-shift measures of DNA damage are presented in Additional file 3: Table S3. While measurements of $\gamma \mathrm{H} 2 \mathrm{AX}$ correlated with those of urinary 1- and 2-OHNap on Thursday, no other significant correlation was observed between measures of exposure, metabolites or DNA damage (Additional file 3: Table S3).

Table 3 presents results of final mixed-effects linear regression models of $\gamma \mathrm{H} 2 \mathrm{AX}$ and urinary $8-\mathrm{OHdG}$ in samples collected from 20 roofers at four different sampling periods (period $1=$ Monday before work, $2=$ Monday after work, $3=$ Thursday before work, $4=$ Thursday after work). None of the dermal exposure measures and urine biomarkers were significant predictors

Table 3 Linear mixed effects models of DNA damage measures in roofers (samples from 20 workers at 4 sampling periods, $n=79$ )

\begin{tabular}{|c|c|c|}
\hline & Estimate (SE) & $p$-value \\
\hline \multicolumn{3}{|l|}{ A) Model for $\gamma H 2 a x^{a}$ (lymphocytes) } \\
\hline \multicolumn{3}{|l|}{ Fixed effects } \\
\hline Intercept & $6.97(0.04)$ & $<0.0001$ \\
\hline Smoker (yes/no) & $0.085(0.04)$ & 0.04 \\
\hline Period 2 (Monday, after work) & $0.09(0.03)$ & 0.008 \\
\hline Period 3 (Thursday, before work) & $0.06(0.03)$ & 0.06 \\
\hline Period 4 (Thursday, after work) & $0.1(0.03)$ & 0.006 \\
\hline Period 1 (Monday, before work) & 0 (ref.) & \\
\hline \multicolumn{3}{|l|}{ Random effects } \\
\hline Between-subject variance & $0.006(0.002)$ & 0.02 \\
\hline Within-subject variance & $0.011(0.002)$ & $<0.0001$ \\
\hline Intraclass correlation coefficient \% & 35.3 & \\
\hline \multicolumn{3}{|l|}{ B) Model for 8-OHdG ${ }^{a}$ (urine) } \\
\hline \multicolumn{3}{|l|}{ Fixed effects } \\
\hline Intercept & $6.99(0.19)$ & $<0.0001$ \\
\hline Urine creatinine $^{a}(\mathrm{~g} / \mathrm{L})$ & $0.68(0.08)$ & $<0.0001$ \\
\hline Period 2 (Monday, after work) & $0.55(0.12)$ & $<0.0001$ \\
\hline Period 3 (Thursday, before work) & $0.13(0.12)$ & 0.27 \\
\hline Period 4 (Thursday, after work) & $0.50(0.12)$ & 0.0002 \\
\hline Period 1 (Monday, before work) & 0 (ref.) & \\
\hline \multicolumn{3}{|l|}{ Random effects } \\
\hline Between-subject variance & $0.007(0.02)$ & 0.32 \\
\hline Within-subject variance & $0.14(0.03)$ & $<0.0001$ \\
\hline Intraclass correlation coefficient \% & 4.8 & \\
\hline
\end{tabular}

\footnotetext{
${ }^{a}$ Analyses are done after (natural) logarithmic transformation
}

of either $\gamma \mathrm{H} 2 \mathrm{AX}$ or of 8 -OHdG in the mixed-effects models and were not retained in final models. For measures of $\gamma \mathrm{H} 2 \mathrm{AX}$, sampling period and cigarette smoking status were significant predictors. Being a smoker corresponded to an $8.5 \%$ increase in logged $\gamma \mathrm{H} 2 \mathrm{AX}$ measurements (Table 3). The percentage of the betweenworker variation of $\gamma \mathrm{H} 2 \mathrm{AX}$ in the $\log$ scale was $35.3 \%$ of the total variance (intraclass correlation coefficient $=35.3 \%$, Table 3 ).

Based on our model (see Table 3 ) the predicted mean value of $\gamma \mathrm{H} 2 \mathrm{AX}$ in samples collected on a Monday afternoon from roofers who are smokers can be calculated as follows: $\ln (\gamma \mathrm{H} 2 \mathrm{AX})=6.97$ (intercept) +0.085 (smoker) + $0.09($ Period 2$)=7.14$ and thus $\gamma \mathrm{H} 2 \mathrm{AX}=1261.4 \mathrm{MFI}$.

For $\gamma \mathrm{H} 2 \mathrm{AX}$, according to the conditional $\mathrm{R}^{2}, 44.3 \%$ of the variation was explained by sampling period alone whereas $45.4 \%$ was explained by period and smoking status; the marginal $\mathrm{R}^{2}$ estimates for these models were 7.6 and $16.4 \%$, respectively (data not shown).

In models of urinary 8-OHdG measurements, cigarette smoking was not a significant predictor, but urine creatinine had a great impact on the levels and was kept in final models. Sampling period also remained a significant predictor. When compared to Monday morning, levels collected on Monday afternoon corresponded to $55 \%$ higher levels of urinary 8-OHdG, and levels collected at the end of the week (period 4) were increased by $50 \%$. The percentage of the betweenworkers variation of 8-OHdG in the log scale was $4.8 \%$ of the total variance (Table 3 ).

Based on our model (see Table 3) the predicted mean value of $8-\mathrm{OHdG}$ in urine samples collected on Monday afternoon from roofers with an average urine creatinine value of $0.1 \mathrm{~g} / \mathrm{L}$ can be calculated as follows: $\ln (8-\mathrm{OHdG} \mu \mathrm{g} / \mathrm{L})=6.99$ (intercept) $+0.68 * 0.1$ (creatinine, $\mathrm{g} / \mathrm{L})+0.55($ period 2$)=7.608$ and thus, urine $8-\mathrm{OHdG}=2014.3 \mu \mathrm{g} / \mathrm{g}$ creatinine.

For the analysis of logged 8-OHdG, according to the conditional $\mathrm{R}^{2}, 18.8 \%$ of the model variation was explained by period alone whereas $56.9 \%$ was explained by period and urine creatinine; the marginal $R^{2}$ estimates for these models were 8.2 and $54.7 \%$, respectively (data not shown).

\section{Discussion}

We have recently shown that urinary $8-\mathrm{OHdG}$ is a promising biomarker reflecting early effects of occupational exposures to PAHs during a single work day [38]. Here we expand our work to include another distinct measure of DNA damage, $\gamma \mathrm{H} 2 \mathrm{AX}$. While the assessment of $\gamma \mathrm{H} 2 \mathrm{AX}$ has been previously used in experimental studies with human cell lines [59-66], this is the first attempt to link human occupational exposures to increased levels of $\gamma \mathrm{H} 2 \mathrm{AX}$. This study is also the first to 
apply high-throughput flow cytometry to quantify $\gamma \mathrm{H} 2 \mathrm{AX}$ in peripheral lymphocytes of workers making it a more feasible option for population-based research. Our results support the idea that work with hot asphalt contributes to higher levels of oxidative DNA damage and DNA double-strand breaks. This effect was more obvious among nonsmokers and on the first week day.

In this study, sampling period, reflecting four different time points within one workweek, was an important predictor of both DNA damage markers. Other important predictors were cigarette smoking for $\gamma \mathrm{H} 2 \mathrm{AX}$ and urinary creatinine for urinary $8-\mathrm{OHdG}$. Our results once again support that urinary $8-\mathrm{OHdG}$ is highly affected by urine dilution. This is an important concern since many times roofers are exposed to heat and can be dehydrated during the course of a single work day.

We also observed that about $35.3 \%$ of the unexplained variance of $\gamma \mathrm{H} 2 \mathrm{AX}$ was between subjects, while this number was only $4.8 \%$ for urinary 8 -OHdG. The proportion of within-subject variance appears larger for urinary 8-OHdG. These two measures cannot be directly compared as they reflect different types of DNA damage (while $\gamma \mathrm{H} 2 \mathrm{AX}$ is a measure of DNA double-strand breaks, 8-OHdG is a measure of oxidative DNA damage) and are measured in different biological media $(\gamma \mathrm{H} 2 \mathrm{AX}$ from lymphocytes and 8-OHdG in urine). However, a low ICC value reflects high within-individual variation of a biomarker and is a sign of poor reproducibility [67]. Other studies also reported high intra-individual variation for urinary 8-OHdG, including in urine samples collected over $24 \mathrm{~h}$ [68-70]. Urinary 8-OHdG is influenced by many individual factors, such as cigarette smoking, dietary factors, or diurnal fluctuations, which may explain some if this high intra-individual variation. Cigarette smoking was not a significant predictor of 8-OHdG levels in our study, but it is possible that other individual factors may have contributed to its variation.

Levels of pyrene on dermal wipes were higher after work when compared to before work measures. This increase was not observed for naphthalene. Consistently, urinary 1-OHPyr levels significantly increased over work hours on Monday, while the increase in urinary naphthalene metabolites was small. Naphthalene is the most abundant PAH in many environments and naphthalene based biomarkers can potentially increase sensitivity of assays. However, our results in this population suggest that environmental influences and cigarette smoking can overwhelm those of occupational exposures to naphthalene. Results of this study are consistent with our previous findings that urinary 1-OHPyr is a promising biomarker of occupational exposures in roofers and that dermal contact can be an important exposure route [38].
Urinary metabolites of PAHs, particularly urinary 1OHPyr, are established biomarkers of occupational exposures. Overall, levels of PAH exposures in this study were lower than previous reports in asphalt exposed workers [71, 72]. While naphthalene metabolites were comparable to levels observed in our prior work with roofers, post-shift levels of urinary 1-OHPyr were much lower in the current study [38]. Here, the highest concentration of urinary 1-OHPyr was observed among nonsmokers in post-shift samples collected on Monday (333.6 ng/l). This is comparable to pre-shift levels of nonsmokers (213 ng/l) observed in our prior work [38] where the highest average levels of post-shift 1-OHPyr was measured as $1002 \mathrm{ng} / \mathrm{l}$ in smokers [38]. In fact, levels of urinary 1-OHPyr in this study are comparable to those observed in the general population [73, 74].

Despite the increase in urinary biomarkers during work hours, we did not observe consistent correlations between measures of exposure, urinary metabolites, and DNA damage, making it difficult to reach a final conclusion on the association between exposure and biomarkers. However, this is possibly related to the overall low occupational exposures observed during the study period. Consistently, Monday morning levels of urinary 8-OHdG were are approximately 36 -fold lower than those observed in our previous study in roofers [38].

Cigarette smoking is an important factor to consider when analyzing $\gamma \mathrm{H} 2 \mathrm{AX}$. The correlation between $\gamma \mathrm{H} 2 \mathrm{AX}$ and urinary metabolites of naphthalene on the second study day was possibly due to their common association with cigarette smoking. This is supported by the fact that levels of urinary 1- and 2-OHNap among smokers were much higher before the work shift on Thursday when compared to levels after the work. It is tempting to limit future evaluations to nonsmokers. However, considering the high proportion of smokers [11] and the challenges of recruiting participants, such a restriction would be impractical in the roofer population. We believe that the best approach is to observe and record cigarette smoking habits and evaluate it as a possible confounder in final analyses.

There are some limitations of this study that constrain the interpretation of results. The most important limitations are the low levels of exposure observed during the study period and the small number of participants. Repeated sampling at four different time points, however, provided us with a larger effective sample size. We also used ANOVA to test for differences between measurements conducted before and after the work shift without adjustment for repeated measures. While before and after-work samples do not reflect identical conditions, they are also not independent. However, this was only a preliminary approach that has been addressed by the use of linear mixed models where the specific 
contrasts of interest have been tested. We also recognize that we are conducting some hypothesis tests without adjustment for multiple comparisons, which in turn might produce a few false positive associations.

Another limitation is the widespread environmental exposure to PAHs and other toxicants that cause DNA damage. 1-OHPyr has been widely viewed as the gold standard biomarker of PAH exposures [75-77]. Naphthalene is present mostly in the gaseous phase and is mainly absorbed through inhalation; pyrene, on the other hand exists both in gas and particulate phase and can be absorbed through inhalation and dermal contact [21]. Usefulness of naphthalene metabolites can be limited if non occupational exposures are common or if occupational exposure is predominantly through the dermal route, in which case urinary 1-OHPyr may serve as a better biomarker.

The PAH biomarkers studied here reflect short-term exposures. The estimated elimination half-lives for urinary 1- \& 2-OHNap and 1-OHPyr are around $4 \mathrm{~h}$ [78] and $13 \mathrm{~h}$ [79], respectively. Because the focus of this study is to link short-term PAH exposures to short-term markers of DNA damage, the rapid elimination of these biomarkers is not expected to restrict our study results.

While $\gamma \mathrm{H} 2 \mathrm{AX}$ is an early response to genotoxic insults, a number of non-occupational factors can contribute to the DNA double strand breaks (DSBs), such as ultraviolet light (UV), environmental chemicals, and even endogenous triggers of DNA damage. Tobacco smoke, a common source of PAHs, is also a potent inducer of DSBs. With the high number of factors influencing $\gamma \mathrm{H} 2 \mathrm{AX}$ response, it is important to distinguish between baseline levels in the general population and $\gamma \mathrm{H} 2 \mathrm{AX}$ kinetics following specific exposures. Two types of $\gamma \mathrm{H} 2 \mathrm{AX}$ foci have been reported previously: the fast transient $\gamma \mathrm{H} 2 \mathrm{AX}$ foci associated with rapid repair which takes place within minutes or hours, and the residual foci that persist for several days or months [80]. The majority of DSBs are repaired during the fast phase usually within minutes, and only about $20 \%$ are repaired during the slower phase [80]. The persistent foci may be the result of slow repair or they may reflect unrepaired damage. Individual factors, such as gender, hormonal response, ethnicity and race, and life style factors (smoking and alcohol consumption), age, and age related diseases such as hypertension or cataracts [81] may further influence $\gamma \mathrm{H} 2 \mathrm{AX}$ repair kinetics [82]. It is also possible that long term occupational exposures induce endogenous DSB formation and contribute to the persistent $\gamma \mathrm{H} 2 \mathrm{AX}$ response. When designing our study we aimed to evaluate exposure and DNA damage at four different time points. This was based on prior knowledge that pre-shift biomarker levels will be higher towards the end of the workweek than those measured at the beginning
[83]. An additional benefit of keeping the four separate time points was the observation that behavioral or individual factors, such as cigarette smoking, can further influence DNA damage levels during the workweek.

\section{Conclusion}

Our overall goal was to explore the usefulness of $\gamma \mathrm{H} 2 \mathrm{AX}$ as a possible marker of DNA damage in workers exposed to PAHs using a high throughput flow cytometry assay. One of our evaluation criteria was its association with exposure data, which we could not observe for $\gamma \mathrm{H} 2 \mathrm{AX}$. Urinary 8-OHdG, a commonly used marker of DNA damage, was also not associated with exposure levels in this group. It is possible that the relatively low levels of exposures may have impacted our analyses. As a second criterion, we evaluated the between- and within-subject variation of $\gamma \mathrm{H} 2 \mathrm{AX}$. Here we observed that $\gamma \mathrm{H} 2 \mathrm{AX}$ has a smaller within-worker variation when compared to urinary 8-OHdG. Our analyses also confirmed that baseline values of $\gamma \mathrm{H} 2 \mathrm{AX}$ are easily detectable in this population, using an inexpensive method such as flow cytometry. Despite the lack of association with exposure data, we propose that $\gamma \mathrm{H} 2 \mathrm{AX}$ is a sensitive biomarker of early DNA damage related to occupational exposures. The low within-subject variation, easy and high throughput methodology makes $\gamma \mathrm{H} 2 \mathrm{AX}$ a feasible alternative in epidemiology studies. We perceive the need for additional studies to understand baseline values of $\gamma \mathrm{H} 2 \mathrm{AX}$, between- and within-individual variation in different study populations, and the impact of developmental and degenerative diseases, as well as dietary, environmental, and life-style factors on this promising biomarker [80]. This will also help develop criteria to distinguish between transient and persistent $\gamma \mathrm{H} 2 \mathrm{AX}$ foci.

\section{Additional files}

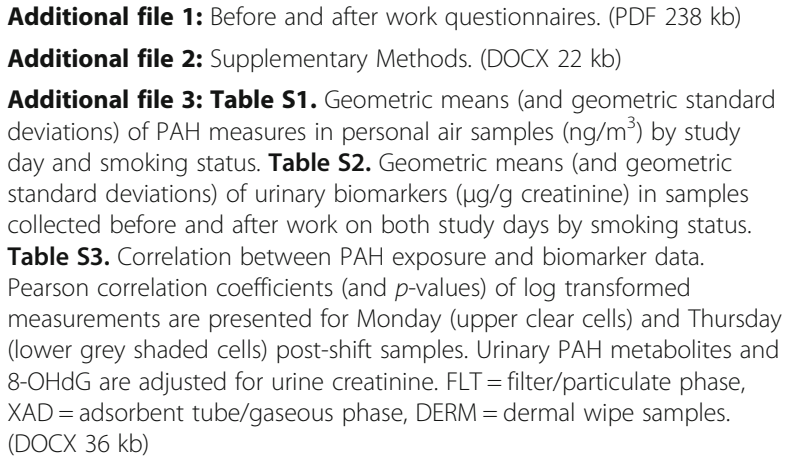

\section{Abbreviations}

1-OHNap: 1-hydroxynaphthalene; 1-OHPyr: 1-hydroxypyrene; 2-OHNap: 2-hydroxynaphthalene; 8-OHdG: 8-hydroxy-2'-deoxyguanosine; ANOVA: Analysis of variance; BaP: benzo(a)pyrene; ELISA: Enzyme-linked immunosorbent assay; FLT: Filter; GC/TOFMS: Gas chromatography with time of flight mass spectrometry; GC-MS: Gas chromatography/mass 
spectrometry; GMs: Geometric means; GSDs: Geometric standard deviations; LOD: Limit of detection; MFI: Mean fluorescence intensity; NIOSH: National Institute of Occupational Safety and Health; OH-PAH: Hydroxylated PAH; PAHs: Polycyclic aromatic hydrocarbons; PBMCs: Peripheral blood mononuclear cells; PBS: Phosphate buffered saline; ROS: Reactive oxygen species; SIM: Selected ion monitoring; SPE: Solid phase extraction; YH2AX: phosphorylated histone H2AX

\section{Acknowledgments}

We thank all the roofers who participated in our study. We also thank the Asphalt Manufacturers Association and the National Roofing Contractors Association for their help during our search for potential study sites. We are grateful to Dr Linda V. Osborn of Heritage Research Group for the analyses of dermal PAHs. Dr Adrie van Bokhoven of University of Colorado Cancer Center provided valuable help in designing bar coded field sampling kits and coordinating lymphocyte isolation procedures.

\section{Funding}

This work was supported by grants from Centers for Disease Control, National Institute of Occupational Health and Safety [R21OH009434 and 42OH009229-07 (MAP ERC pilot grant)]. Its contents are solely the responsibility of the authors and do not necessarily represent the official views of Centers for Disease Control.

\section{Availability of data and materials}

Data sets are not publicly available. Data will not be shared in compliance with the University of Colorado's IRB (COMIRB) approved protocol.

\section{Authors' contributions}

BS conceptualized and designed the study, supervised field work and laboratory analyses, conducted statistical analyses and drafted the manuscript. SB conducted analyses of DNA damage measures $(\mathrm{\gamma H} 2 \mathrm{ax}$ and $8-\mathrm{OHdG})$, assisted with data entry and manuscript draft. GD conducted analyses of urinary analytes and of air PAHs. JV participated in study design and provided guidance for the collection of personal air samples. EJ participated in study design, reviewed statistical analyses and interpretations. RG collected dermal wipe samples, assisted during field work and final data entry. All authors read and approved the final manuscript.

\section{Competing interests}

The authors declare that they have no competing interests.

\section{Consent for publication}

Not applicable.

\section{Ethics approval and consent to participate}

Potential participants were informed about the study at the site and those who signed the informed consent under University of Colorado's IRB (COMIRB) approved protocol (COMIRB Protocol \# 12-0443) were recruited.

\section{Author details}

${ }^{1}$ Department of Environmental and Occupational Health, Colorado School of Public Health, University of Colorado Denver, Denver, USA. ${ }^{2}$ Department of Epidemiology, Colorado School of Public Health, University of Colorado Denver, Denver, USA. ${ }^{3}$ Analytical Toxicology Laboratory, Center for Environmental Medicine, Colorado State University, Fort Collins, USA. ${ }^{4}$ Department of Mechanical Engineering, Colorado State University, Fort Collins, USA. ${ }^{5}$ Department of Biostatistics and Informatics, Colorado School of Public Health, University of Colorado Denver, Denver, USA. ${ }^{6}$ Colorado School of Public Health, University of Colorado Anschutz Medical Campus, Mail Stop B119-V20, 12850 East Montview Boulevard, Rm. V20-3126, Aurora, CO 80045, USA.

Received: 21 June 2016 Accepted: 10 October 2016 Published online: 20 October 2016

\section{References}

1. Poirier MC. Chemical-induced DNA damage and human cancer risk. Discov Med. 2012;14(77):283-8.

2. Bonner WM, Redon CE, Dickey JS, Nakamura AJ, Sedelnikova OA, Solier S, Pommier Y. GammaH2AX and cancer. Nat Rev Cancer. 2008;8(12):957-67.
3. Wang E, Dement JM, Lipscomb H. Mortality among North Carolina construction workers, 1988-1994. Appl Occup Environ Hyg. 1999;14(1):45-58.

4. Partanen T, Boffetta P. Cancer risk in asphalt workers and roofers: review and meta-analysis of epidemiologic studies. Am J Ind Med. 1994;26(6):721-40.

5. Robinson C, Stern F, Halperin W, Venable H, Petersen M, Frazier T, Burnett C, Lalich N, Salg J, Sestito J, et al. Assessment of mortality in the construction industry in the United States, 1984-1986. Am J Ind Med. 1995;28(1):49-70.

6. Boffetta P, Burstyn I, Partanen T, Kromhout H, Svane O, Langard S, Jarvholm B, Frentzel-Beyme R, Kauppinen T, Stucker I, et al. Cancer mortality among European asphalt workers: an international epidemiological study. II. Exposure to bitumen fume and other agents. Am J Ind Med. 2003;43(1):28-39.

7. Boffetta P, Burstyn I, Partanen T, Kromhout H, Svane O, Langard S, Jarvholm B, Frentzel-Beyme R, Kauppinen T, Stucker I, et al. Cancer mortality among European asphalt workers: an international epidemiological study. I. Results of the analysis based on job titles. Am J Ind Med. 2003;43(1):18-27.

8. Deschamps F, Barouh M, Deslee G, Prevost A, Munck JN. Estimates of work-related cancers in workers exposed to carcinogens. Occup Med (Lond). 2006:56(3):204-9.

9. McClean MD, Rinehart RD, Ngo L, Eisen EA, Kelsey KT, Herrick RF. Inhalation and dermal exposure among asphalt paving workers. Ann Occup Hyg. 2004;48(8):663-71.

10. McClean MD, Wiencke JK, Kelsey KT, Varkonyi A, Ngo L, Eisen EA, Herrick RF. DNA adducts among asphalt paving workers. Ann Occup Hyg. 2007:51(1): 27-34. Epub 2006 Oct 17.

11. Lee DJ, LeBlanc W, Fleming LE, Gomez-Marin O, Pitman T. Trends in US smoking rates in occupational groups: the National Health Interview Survey 1987-1994. J Occup Environ Med. 2004;46(6):538-48.

12. Fuchs J, Hengstler JG, Boettler G, Oesch F. Primary DNA damage in peripheral mononuclear blood cells of workers exposed to bitumen-based products. Int Arch Occup Environ Health. 1996;68(3):141-6.

13. Burgaz S, Erdem O, Karahalil B, Karakaya AE. Cytogenetic biomonitoring of workers exposed to bitumen fumes. Mutat Res. 1998;419(1-3):123-30.

14. Toraason M, Hayden C, Marlow D, Rinehart R, Mathias P, Werren D, Olsen LD, Neumeister CE, Mathews ES, Cheever KL, et al. DNA strand breaks, oxidative damage, and 1-OH pyrene in roofers with coal-tar pitch dust and/or asphalt fume exposure. Int Arch Occup Environ Health. 2001;74(6):396-404.

15. Clement International Corporation, United States. Agency for Toxic Substances and Disease Registry. Toxicological profile for polycyclic aromatic hydrocarbons draft. Atlanta: The Agency; 1993.

16. Lane DA. Polycyclic aromatic hydrocarbons: atmospheric physics and chemistry. Chapter 5 in: Organic chemistry of the atmosphere. Boston: CRC Press Inc; 1991.

17. Lesage J, Perrault G, Durand P. Evaluation of worker exposure to polycyclic aromatic hydrocarbons. Am Ind Hyg Assoc J. 1987;48(9):753-9.

18. Boogaard PJ, van Sittert NJ. Urinary 1-hydroxypyrene as biomarker of exposure to polycyclic aromatic hydrocarbons in workers in petrochemical industries: baseline values and dermal uptake. Sci Total Environ. 1995:163(1-3):203-9.

19. Elovaara E, Heikkila P, Pyy L, Mutanen P, Riihimaki V. Significance of dermal and respiratory uptake in creosote workers: exposure to polycyclic aromatic hydrocarbons and urinary excretion of 1-hydroxypyrene. Occup Environ Med. 1995:52(3):196-203.

20. Van Rooij JG, Veeger MM, Bodelier-Bade MM, Scheepers PT, Jongeneelen FJ. Smoking and dietary intake of polycyclic aromatic hydrocarbons as sources of interindividual variability in the baseline excretion of 1-hydroxypyrene in urine. Int Arch Occup Environ Health. 1994;66(1):55-65.

21. VanRooij JG, Bodelier-Bade MM, Jongeneelen FJ. Estimation of individual dermal and respiratory uptake of polycyclic aromatic hydrocarbons in 12 coke oven workers. Br J Ind Med. 1993:50(7):623-32.

22. Becher $\mathrm{G}$, Bjorseth $\mathrm{A}$. Determination of exposure to polycyclic aromatic hydrocarbons by analysis of human urine. Cancer Lett. 1983;17(3):301-11.

23. Jongeneelen FJ, Bos RP, Anzion RB, Theuws JL, Henderson PT. Biological monitoring of polycyclic aromatic hydrocarbons. Metabolites in urine. Scand J Work Environ Health. 1986;12(2):137-43.

24. Hansen AM, Christensen JM, Sherson D. Estimation of reference values for urinary 1-hydroxypyrene and alpha-naphthol in Danish workers. Sci Total Environ. 1995:163(1-3):211-9.

25. Bjoorseth A, Bjorseth O, Fjeldstad PE. Polycyclic aromatic hydrocarbons in the work atmosphere. II. Determination in a coke plant. Scand J Work Environ Health. 1978;4(3):224-36 
26. Bjorseth A, Bjorseth O, Fjeldstad PE. Polycyclic aromatic hydrocarbons in the work atmosphere. I. Determination in an aluminum reduction plant. Scand J Work Environ Health. 1978;4(3):212-23.

27. Hansen AM, Omland O, Poulsen OM, Sherson D, Sigsgaard T, Christensen JM, Overgaard E. Correlation between work process-related exposure to polycyclic aromatic hydrocarbons and urinary levels of alpha-naphthol, beta-naphthylamine and 1-hydroxypyrene in iron foundry workers. Int Arch Occup Environ Health. 1994;65(6):385-94.

28. Kim H, Cho SH, Kang JW, Kim YD, Nan HM, Lee CH, Lee H, Kawamoto T. Urinary 1-hydroxypyrene and 2-naphthol concentrations in male Koreans. Int Arch Occup Environ Health. 2001;74(1):59-62.

29. Rappaport SM, Waidyanatha S, Serdar B. Naphthalene and its biomarkers as measures of occupational exposure to polycyclic aromatic hydrocarbons. J Environ Monit. 2004;6(5):413-6.

30. Kryston TB, Georgiev AB, Pissis P, Georgakilas AG. Role of oxidative stress and DNA damage in human carcinogenesis. Mutat Res. 2011;711(1-2):193-201.

31. Wu LL, Chiou CC, Chang PY, Wu JT. Urinary 8-OHdG: a marker of oxidative stress to DNA and a risk factor for cancer, atherosclerosis and diabetics. Clin Chim Acta. 2004;339(1-2):1-9.

32. Floyd RA. The role of 8-hydroxyguanine in carcinogenesis. Carcinogenesis. 1990;11(9):1447-50.

33. Valavanidis A, Vlachogianni T, Fiotakis C. 8-hydroxy-2' -deoxyguanosine (8$\mathrm{OHdG}$ ): a critical biomarker of oxidative stress and carcinogenesis. J Environ Sci Health C Environ Carcinog Ecotoxicol Rev. 2009;27(2):120-39.

34. Cooke MS, Evans MD, Herbert KE, Lunec J. Urinary 8-oxo-2'deoxyguanosine-source, significance and supplements. Free Radic Res. 2000;32(5):381-97.

35. Pilger A, Rudiger HW. 8-Hydroxy-2'-deoxyguanosine as a marker of oxidative DNA damage related to occupational and environmental exposures. Int Arch Occup Environ Health. 2006:80(1):1-15.

36. Cavallo D, Ursini CL, Bavazzano P, Cassinelli C, Frattini A, Perniconi B, Di Francesco A, Ciervo A, Rondinone B, lavicoli S. Sister chromatid exchange and oxidative DNA damage in paving workers exposed to PAHs. Ann Occup Hyg. 2006;50(3):211-8.

37. Marczynski B, Raulf-Heimsoth M, Preuss R, Kappler M, Schott K, Pesch B, Zoubek G, Hahn JU, Mensing T, Angerer J, et al. Assessment of DNA damage in WBCs of workers occupationally exposed to fumes and aerosols of bitumen. Cancer Epidemiol Biomarkers Prev. 2006;15(4):645-51.

38. Serdar B, Lee D, Dou Z. Biomarkers of exposure to polycyclic aromatic hydrocarbons (PAHs) and DNA damage: a cross-sectional pilot study among roofers in South Florida. BMJ Open. 2012;2(4). doi: 10.1136/bmjopen-2012-001318.

39. Sakano N, Wang DH, Takahashi N, Wang B, Sauriasari R, Kanbara S, Sato Y, Takigawa T, Takaki J, Ogino K. Oxidative stress biomarkers and lifestyles in Japanese healthy people. J Clin Biochem Nutr. 2009;44(2):185-95.

40. Valdiglesias V, Giunta S, Fenech M, Neri M, Bonassi S. gamma H2AX as a marker of DNA double strand breaks and genomic instability in human population studies. Mutat Res Rev Mutat Res. 2013;753(1):24-40.

41. Barnard S, Ainsbury EA, Al-Hafidh J, Hadjidekova V, Hristova R, Lindholm C, Monteiro Gil O, Moquet J, Moreno M, Rossler U et al. The first gamma-H2ax biodosimetry intercomparison exercise of the developing European biodosimetry network Reneb. Radiat Prot Dosimetry. 2015;164(3):265-70. doi: 10.1093/rpd/ncu259. Epub 2014 Aug 12.

42. Rothkamm K, Barnard S, Ainsbury EA, Al-Hafidh J, Barquinero JF, Lindholm C, Moquet J, Perala M, Roch-Lefevre S, Scherthan H, et al. Manual versus automated gamma-H2AX foci analysis across five European laboratories: can this assay be used for rapid biodosimetry in a large scale radiation accident? Mutat Res. 2013;756(1-2):170-3

43. Vandevoorde C, Franck C, Bacher K, Breysem L, Smet MH, Ernst C, De Backer A, Van De Moortele K, Smeets $P$, Thierens $H$. gamma-H2AX foci as in vivo effect biomarker in children emphasize the importance to minimize $x$-ray doses in paediatric CT imaging. Eur Radiol. 2015;25(3):800-11.

44. Albino AP, Jorgensen ED, Rainey P, Gillman G, Clark TJ, Gietl D, Zhao H, Traganos F, Darzynkiewicz Z. gammaH2AX: a potential DNA damage response biomarker for assessing toxicological risk of tobacco products. Mutat Res. 2009;678(1):43-52.

45. Ganapathy V, Ramachandran I, Rubenstein DA, Queimado L. Detection of in vivo DNA damage induced by very low doses of mainstream and sidestream smoke extracts using a novel assay. Am J Prev Med. 2015:48(1):S102-10.

46. Longhin E, Pezzolato E, Mantecca P, Holme JA, Franzetti A, Camatini M, Gualtieri M. Season linked responses to fine and quasi-ultrafine Milan PM in cultured cells. Toxicol In Vitro. 2013;27(2):551-9.
47. Harada A, Matsuzaki K, Takeiri A, Mishima M. The predominant role of apoptosis in gamma H2AX formation induced by aneugens is useful for distinguishing aneugens from clastogens. Mutat Res Genet Toxicol Environ Mutagen. 2014;771:23-9.

48. Sanchez-Flores M, Pasaro E, Bonassi S, Laffon B, Valdiglesias V. gammaH2AX Assay as DNA damage biomarker for human population studies: defining experimental conditions. Toxicol Sci. 2015;144(2):406-13.

49. Matthaios D, Hountis P, Karakitsos P, Bouros D, Kakolyris S. H2AX a promising biomarker for lung cancer: a review. Cancer Invest. 2013;31(9):582-99.

50. Xu E, Gong Y, Gu J, Jie L, Ajani JA, Wu X. Risk assessment of esophageal adenocarcinoma using gamma-H2AX assay. Cancer Epidemiol Biomarkers Prev. 2013;22(10):1797-804

51. Redon CE, Weyemi U, Parekh PR, Huang D, Burrell AS, Bonner WM. gamma$\mathrm{H} 2 \mathrm{AX}$ and other histone post-translational modifications in the clinic. Biochim Biophys Acta. 2012;1819(7):743-56.

52. Muslimovic A, Johansson $P$, Hammarsten O. Measurement of H2AX phosphorylation as a marker of ionizing radiation induced cell damage. In: Nenoi DM, editor. Current topics in ionizing radiation research. ISBN: 978953-51-0196-3. InTech; 2012. Available from: http://www.intechopen.com/ books/currenttopics-in-ionizing-radiation-research/measurement-ofh2axphosphorylation-as-a-marker-of-ionizing-radiationinduced-cell-damage.

53. Heylmann D, Kaina B. The gammaH2AX DNA damage assay from a drop of blood. Sci Rep. 2016;6:22682.

54. Hulka BS. ASPO distinguished achievement award lecture. Epidemiological studies using biological markers: issues for epidemiologists. Cancer Epidemiol Biomarkers Prev. 1991;1(1):13-9.

55. Romanoff LC, Li Z, Young KJ, Blakely 3rd NC, Patterson Jr DG, Sandau CD. Automated solid-phase extraction method for measuring urinary polycyclic aromatic hydrocarbon metabolites in human biomonitoring using isotopedilution gas chromatography high-resolution mass spectrometry. J Chromatogr B Anal Technol Biomed Life Sci. 2006;835(1-2):47-54.

56. Cavallari JM, Osborn LV, Snawder JE, Kriech AJ, Olsen LD, Herrick RF, McClean MD. Predictors of dermal exposures to polycyclic aromatic compounds among hot-mix asphalt paving workers. Ann Occup Hyg. 2012;56(2):125-37.

57. Hornung RW, Reed LD. Estimation of average concentration in the presence of nondetectable values. Appl Occup Environ Hyg. 1990;5(1):46-51.

58. Nakagawa $S$, Schielzeth $H$. A general and simple method for obtaining $R^{2}$ from generalized linear mixed-effects models. Methods Ecol Evol. 2013;4:133-42.

59. Mattsson A, Jernstrom B, Cotgreave IA, Bajak E. H2AX phosphorylation in A549 cells induced by the bulky and stable DNA adducts of benzo[a]pyrene and dibenzo[a, I]pyrene diol epoxides. Chem Biol Interact. 2009;177(1):40-7.

60. Mattsson A, Lundstedt S, Stenius U. Exposure of HepG2 cells to low levels of PAH-containing extracts from contaminated soils results in unpredictable genotoxic stress responses. Environ Mol Mutagen. 2009;50(4):337-48.

61. Hruba E, Trilecova L, Marvanova S, Kremar P, Vykopalova L, Milcova A, Libalova H, Topinka J, Starsichova A, Soucek K, et al. Genotoxic polycyclic aromatic hydrocarbons fail to induce the p53-dependent DNA damage response, apoptosis or cell-cycle arrest in human prostate carcinoma LNCaP cells. Toxicol Lett. 2010;197(3):227-35.

62. Audebert M, Zeman F, Beaudoin R, Pery A, Cravedi JP. Comparative potency approach based on $\mathrm{H} 2 \mathrm{AX}$ assay for estimating the genotoxicity of polycyclic aromatic hydrocarbons. Toxicol Appl Pharmacol. 2012;260(1):58-64.

63. Jamin EL, Riu A, Douki T, Debrauwer L, Cravedi JP, Zalko D, Audebert M. Combined genotoxic effects of a polycyclic aromatic hydrocarbon (B(a)P) and an heterocyclic amine (PhIP) in relation to colorectal carcinogenesis. PLoS One. 2013;8(3). doi: 10.1371/journal.pone.0058591.

64. Wilk A, Waligorski P, Lassak A, Vashistha H, Lirette D, Tate D, Zea AH, Koochekpour S, Rodriguez P, Meggs LG, et al. Polycyclic aromatic hydrocarbons-induced ROS accumulation enhances mutagenic potential of Tantigen from human polyomavirus JC. J Cell Physiol. 2013;228(11):2127-38.

65. Rossner P, Rossnerova A, Beskid O, Tabashidze N, Libalova H, Uhlirova K, Topinka J, Sram RJ. Nonhomologous DNA end joining and chromosome aberrations in human embryonic lung fibroblasts treated with environmental pollutants. Mutat Res Fundam Mol Mech Mutagen. 2014;763:28-38.

66. Yang L, Liu G, Lin Z, Wang Y, He H, Liu T, Kamp DW. Pro-inflammatory response and oxidative stress induced by specific components in ambient particulate matter in human bronchial epithelial cells. Environ Toxicol. 2016; 31(8):923-36. doi:10.1002/tox.22102. Epub 2014 Dec 23. 
67. Attfield KR, Hughes MD, Spengler JD, Lu C. Within- and between-child variation in repeated urinary pesticide metabolite measurements over a 1-year period. Environ Health Perspect. 2014;122(2):201-6.

68. Pilger A, Germadnik D, Riedel K, Meger-Kossien I, Scherer G, Rudiger HW. Longitudinal study of urinary 8-hydroxy-2'-deoxyguanosine excretion in healthy adults. Free Radic Res. 2001;35(3):273-80.

69. Zanolin ME, Girardi P, Degan P, Rava M, Olivieri M, Di Gennaro G, Nicolis M De Marco R. Measurement of a urinary marker (8-hydroxydeoxy-guanosine, 8-OHdG) of DNA oxidative stress in epidemiological surveys: a pilot study. Int J Biol Markers. 2015;30(3):e341-5.

70. Chien YC, Yeh CT. Excretion characteristics of urinary 8hydroxydeoxyguanosine after dietary exposure to polycyclic aromatic hydrocarbons. Environ Mol Mutagen. 2010;51(3):243-50.

71. Cavallari JM, Osborn LV, Snawder JE, Kriech AJ, Olsen LD, Herrick RF, McClean MD. Predictors of airborne exposures to polycyclic aromatic compounds and total organic matter among hot-mix asphalt paving workers and influence of work conditions and practices. Ann Occup Hyg. 2012;56(2):138-47.

72. Breuer D, Hahn JU, Hober D, Emmel C, Musanke U, Ruhl R, Spickenheuer A, Raulf-Heimsoth M, Bramer R, Seidel A, et al. Air sampling and determination of vapours and aerosols of bitumen and polycyclic aromatic hydrocarbons in the Human Bitumen Study. Arch Toxicol. 2011;85 Suppl 1:S11-20.

73. Roggi C, Minoia C, Sciarra GF, Apostoli P, Maccarini L, Magnaghi S, Cenni A, Fonte A, Nidasio GF, Micoli G. Urinary 1-hydroxypyrene as a marker of exposure to pyrene: an epidemiological survey on a general population group. Sci Total Environ. 1997;199(3):247-54.

74. Huang W, Grainger J, Patterson Jr DG, Turner WE, Caudill SP, Needham LL, Pirkle JL, Sampson EJ. Comparison of 1-hydroxypyrene exposure in the US population with that in occupational exposure studies. Int Arch Occup Environ Health. 2004;77(7):491-8.

75. Jongeneelen FJ. Methods for routine biological monitoring of carcinogenic PAH-mixtures. Sci Total Environ. 1997;199(1-2):141-9.

76. Ifegwu C, Osunjaye K, Fashogbon F, Oke K, Adeniyi A, Anyakora C. Urinary 1-hydroxypyrene as a biomarker to carcinogenic polycyclic aromatic hydrocarbon exposure. Biomarkers Cancer. 2012;4:7-17.

77. Viau MB. Urinary 1-hydroxypyrene as a biomarker of exposure to polycyclic aromatic hydrocarbons: biological monitoring strategies and methodology for determining biological exposure indices for various work environments. Biomarkers. 1999:4(3):159-87.

78. Bieniek $\mathrm{G}$. The presence of 1-naphthol in the urine of industrial workers exposed to naphthalene. Occup Environ Med. 1994;51(5):357-9.

79. Boogaard PJ, van Sittert NJ. Exposure to polycyclic aromatic hydrocarbons in petrochemical industries by measurement of urinary 1-hydroxypyrene. Occup Environ Med. 1994;51(4):250-8.

80. Siddiqui MS, Francois M, Fenech MF, Leifert WR. Persistent gammaH2AX: a promising molecular marker of DNA damage and aging. Mutat Res Rev Mutat Res. 2015;766:1-19.

81. Schurman SH, Dunn CA, Greaves R, Yu B, Ferrucci L, Croteau DL, Seidman $\mathrm{MM}, \mathrm{Bohr}$ VA. Age-related disease association of endogenous gamma-H2AX foci in mononuclear cells derived from leukapheresis. PLoS One. 2012;7(9):e45728.

82. Sharma PM, Ponnaiya B, Taveras M, Shuryak I, Turner H, Brenner DJ. Correction: high throughput measurement of gammaH2AX DSB repair kinetics in a healthy human population. PLoS One. 2015;10(6):e0131620.

83. Hansen AM, Mathiesen L, Pedersen M, Knudsen LE. Urinary 1-hydroxypyrene (1-HP) in environmental and occupational studies-a review. Int J Hyg Environ Health. 2008:211(5-6):471-503.

\section{Submit your next manuscript to BioMed Central and we will help you at every step:}

- We accept pre-submission inquiries

- Our selector tool helps you to find the most relevant journal

- We provide round the clock customer support

- Convenient online submission

- Thorough peer review

- Inclusion in PubMed and all major indexing services

- Maximum visibility for your research

Submit your manuscript at www.biomedcentral.com/submit
Biomed Central 